\title{
ANNOUNCEMENTS
}

The 2nd International Conference of THE HOSPITAL INFECTION SOCIETY

will be held in LONDON on September 2nd-6th, 1990

In 1987, when the 1st International Conference was held, over 1000 delegates attended the event which proved to be remarkably successful. Their primary activities were related to hospital infection, its management and prevention.

The 2nd International Conference will be attended by physicians, medical microbiologists, research scientists and hospital infection control personnel from many parts of the world. The scientific programme will address the current interests and concerns in the field of microbial disease, and will comprise symposia, workshops, free communications and posters.

In addition to the scientific programme mentioned above, the Conference will be supplemented by a major trade exhibition which will afford exhibiting companies a unique opportunity to address this market sector.

Further information and a copy of the registration form may be obtained from the Conference Secretariat:

Conference Associates HIS, Congress House,

55 New Cavendish Street, London W1M 7RE, United Kingdom.

Telephone 014860531 , Telefax 019357559.

Institute of Medical Laboratory Sciences

Sheffield Branch, Microbiology Discussion Group

\section{MICROBE 90}

Ranmoor Hall of Residence, University of Sheffield

13-16 September 1990

Friday September 14

a.m. New Technology

p.m. Microbiology and the Community

Saturday September 15

a.m. Antimicrobial Therapy/Virology (concurrent)

p.m. AIDS Update

Sunday September 16

a.m. New Diseases

Posters are invited for open presentation and will be displayed throughout the meeting.

Registration fee (including meals, accommodation, social programme and symposium dinner) $£ 95$.

Further details and application forms are available from:

Mr M. Preston

11 Buckingham Way

Maltby, Rotherham

S. Yorks S66 7EA or

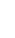

Mr C. J. P. Brazier

Head MLSO

Public Health Laboratory

Northern General Hospital

Herries Road

Sheffield S5 7AU

Tel : 0742-437749 


\section{2nd Western Pacific Congress on Infectious Diseases and Chemotherapy}

11 - 14 December 1990 Jomtien-Pattaya, Thailand

The programme will include major Symposia and Free Communications (posters and oral presentations) on: Infectious Diseases (including community and hospital acquired, paediatric and adult, surgical, genitourinary and tropical infections) Microbiological Laboratory Techniques

Antimicrobial Chemotherapy Immunology, Immunotherapy and Vaccines

Abstracts should be submitted by 1 August 1990

Further information from:

Dr $P$ Jayanetra

EPIDC Secretariat Office, Department of Pathology, Faculty of Medicine

Ramathibodi Hospital

Rama VI Road, Bangkok 10400, Thailand 